Revue

Revue de l'histoire des religions

de Ihistoire

des religions

$1 \mid 2008$

Varia

\title{
Identités franciscaines à l'âge des Réformes, sous la direction de Frédéric Meyer et Ludovic Viallet
}

\section{Guy Bedouelle}

\section{OpenEdition \\ Journals}

Édition électronique

URL : http://journals.openedition.org/rhr/5843

DOI : $10.4000 /$ rhr.5843

ISSN : 2105-2573

Éditeur

Armand Colin

\section{Édition imprimée}

Date de publication : 1 mars 2008

Pagination : 138-139

ISBN : 978-2200-92443-0

ISSN : 0035-1423

Référence électronique

Guy Bedouelle, «Identités franciscaines à l'âge des Réformes, sous la direction de Frédéric Meyer et Ludovic Viallet », Revue de l'histoire des religions [En ligne], 1 | 2008, mis en ligne le 12 janvier 2010, consulté le 22 septembre 2020. URL : http://journals.openedition.org/rhr/5843 ; DOI : https://doi.org/ $10.4000 /$ rhr.5843

Ce document a été généré automatiquement le 22 septembre 2020.

Tous droits réservés 


\title{
Identités franciscaines à l'âge des Réformes, sous la direction de Frédéric Meyer et Ludovic Viallet
}

\author{
Guy Bedouelle
}

\section{RÉFÉRENCE}

Identités franciscaines à l'âge des Réformes, sous la direction de Frédéric Meyeret Ludovic Viallet,Clermont-Ferrand, Presses universitaires Blaise Pascal, 2005, 23,5 cm, 536 p. (« Histoires croisées »), $39 €$.

1 Vingt-quatre auteurs écrivant en cinq langues (majoritairement français, mais aussi italien, anglais, allemand et espagnol) dans une grande diversité d'approches, ont contribué à ce livre issu de deux colloques tenus à Clermont-Ferrand en 2003 et à Chambéry en 2004. Leurs communications ont été réparties en quatre ensembles. Il y a d'abord «La vie franciscaine en choix et en débats », couvrant les réformes internes aux branches de l'ordre des Mineurs, du xIV au xvII siècle. La deuxième partie s'intitule «La transformation du paysage franciscain. Réseaux dévots et volontés princières » et nous mène de la France à la Pologne, de l'Espagne à la Savoie. Vient ensuite une partie sur l'architecture et les bibliothèques: "Simplicitas ou superfluitas? Le livre et la pierre ». Enfin, le dernier ensemble traite de «l'institution au temps des Réformes » en France et en Hongrie. Un essai de bibliographie sur les mouvements de réforme de l'ordre franciscain aux $\mathrm{Xv}^{\mathrm{e}}-\mathrm{XVI}^{\mathrm{e}}$ siècles, est ensuite proposé, avec un classement selon les divers espaces géographiques. Un index regroupant les noms des franciscains évoqués achève cet ouvrage.

On peut imaginer le tour de force de tenter de donner une certaine unité à ces contributions si diverses et parfois brèves. Il n'a pas fallu moins d'une Préface, d'une Introduction et d'une Conclusion, pour s'y essayer. Dans leur Préface, soulignant que ce livre enjambe la frontière souvent étanche entre médiévistes et modernistes, Nicole 
Bériou et Bernard Dompnier invitent précisément le lecteur à relever le défi de chercher « au cœur de l'intense foisonnement de l'histoire franciscaine, les lectures multiples d'un message unique, celui du Pauvre d'Assise » (p. 9). Il convient donc de se situer dans l'esprit « d'un véritable programme collectif de recherche » (p. 11).

Les éditeurs du livre, quant à eux, considèrent les communications publiées comme des «jalons pour une enquête ». Mais ils arrivent avec talent à proposer quelques cadres et quelques idées-force selon les espaces considérés. Ne mentionnons ici que la périodisation retenue pour rendre compte de l'essor de l'observance franciscaine dans ses rapports avec les Conventuels: "Ainsi pourrait-on proposer trois phases principales; un temps d'émergence et de spectaculaire progression, dans une large première moitié $\mathrm{du} \mathrm{Xv}^{\mathrm{e}}$ siècle; un temps d'affrontements et de morcellement jusque dans la décennie 1560...; enfin le nouvel élan des années 1570-1580, décisif pour la constitution d'un paysage franciscain stable et la cristallisation d'identités " (p. 15). Dans sa conclusion, G. G. Merlo s'interroge sur les liens qui existent entre identité, identités, et le terme " franciscanisme ».

Il semble pourtant qu'au-delà de ces exercices, l'intérêt de l'ouvrage est tout simplement de regrouper commodément des études fouillées et neuves, telles, par exemple, la géographie des observances (Jean-Marie Le Gall), l'examen des changements d'habit, c'est-à-dire du passage d'une branche à l'autre chez les Capucins à partir des requêtes conservées aux Archives vaticanes (Bernard Dompnier), les mises en œuvre architecturales à Paris (Panayota Volti), etc. Il y a aussi des synthèses bien établies sur des sujets précis (Pierre Moracchini, dans ses deux articles sur les Observants masculins et féminins, ou Charles-Marie de La Roncière pour le $\mathrm{xv}^{\mathrm{e}}$ siècle). On peut regretter toutefois l'absence de toute approche comparative : que se passe-t-il à la même époque chez les autres "mendiants ", dominicains, augustins ou carmes ? On en trouve des traces dans les projets que Robert Sauzet expose ici d'une édition plus complète de son ouvrage Mendiants et Réformes. Les réguliers mendiants, acteurs du changement religieux dans le royaume de France (1480-1560), Tours, 1994. Ces réalisations et ces programmes témoignent de la vitalité de ce champ de recherche.

\section{AUTEURS}

\section{GUY BEDOUELLE}

Université de Fribourg/Suisse 